\title{
PHYSICAL, CHEMICAL AND SESNORY PROPERTIES OF FLAKES (GARI) PREPARED FROM REFRIGERATED CASSAVA ROOTS
}

\author{
*1,2Oyeyinka, S. A., ${ }^{2}$ Adesoye, A. A., ${ }^{4}$ Oladipo, J. O., ${ }^{2}$ Akintayo, O. A., \\ ${ }^{5}$ Adediran, O. J., ${ }^{3}$ Badmos, A. A., ${ }^{2}$ Balogun, M. A., ${ }^{2}$ Ojo, P. K., ${ }^{3}$ Adeloye, A. A., \\ and ${ }^{1}$ Diarra, S. S. \\ ${ }^{1}$ School of Agriculture and Food Technology, University of the South Pacific, \\ Apia, Samoa \\ ${ }^{2}$ Department of Home Economics and Food Science, University of Ilorin, Nigeria \\ ${ }^{3}$ Department of Animal Production, University of Ilorin, Nigeria \\ ${ }^{4}$ Department of Industrial Chemistry, University of Ilorin, Nigeria \\ ${ }^{5}$ School of Tourism, Hospitality and Event Management, Kwara State \\ University, Nigeria \\ *Corresponding Author: sartf2001@yahoo.com
}

\begin{abstract}
Cassava is a tropical crop that can be processed into a variety of products including flakes popularly called gari. Gari is a product obtained from cassava root by fermentation, but the root from which the gari is obtained spoils rapidly. Efforts have been made to extend the shelf life of the root through the use of traditional and improved storage techniques, for example storage in boxes, freezing and refrigeration. However, the quality of the products from refrigerated roots, such as gari, has not been reported. In this study, cassava roots were refrigerated for a period of three weeks and the physicochemical properties of gari from the stored roots were determined. With the exception of the carbohydrate content which was very similar (approx. 88\%), refrigeration of cassava roots significantly $(p<0.05)$ affected the physical and chemical properties of the resulting gari. The cyanide content decreased from 2.96 to 1.90 $\mathrm{mg} / \mathrm{kg}$ with increase in refrigeration period, while the functional properties including bulk densities and swelling power were only slightly affected. Cassava roots can be refrigerated for a period of two weeks without substantial changes in the eating quality of the resulting gari, if the storage condition is closely monitored. Future studies are required to investigate the physicochemical properties of other valuable products from refrigerated cassava roots to determine their potentials in food and non-food applications.
\end{abstract}

Keyword: Cassava; Functional; Gari; Refrigeration; Pasting; Sensory 


\section{INTRODUCTION}

Cassava (Manihot esculenta) is a major crop in the tropics grown for its edible root. It is the second most important tropical root crop in West Africa (Adisa et al., 2015; Falola et al., 2017). However, cassava spoils rapidly because of its high moisture content which may vary between 61.00 and $90.15 \%$ (lbegbulem and Chikezie, 2018; Laya et al., 2018; Oyeyinka et al., 2020). Deterioration which sets in immediately after harvest is a major challenge limiting commercial production of cassava (Uchechukwu-Agua et al., 2015). The rapid post-harvest deterioration of cassava roots, which usually prevents their storage in the fresh state for more than 2-3 days, is poorly understood. Several modern and traditional methods of storing cassava roots have been developed to control the deterioration of cassava roots. Modern methods include waxing, chemical treatment, controlled atmosphere, deep freezing and refrigeration (Uchechukwu-Agua et al., 2015). Subsistence farmers leave cassava roots in the ground until needed, or if storage is required after harvesting as a traditional means, re-bury the roots in a trench (Karim et al., 2009). Due to its perishability, cassava root is rapidly processed into shelf-stable products such as fufu, elubo and gari (Balogun et al., 2012; Oyeyinka et al., 2019b) with low moisture content to enhance stability and longterm storage (Uchechukwu-Agua et al., 2015). Among these products, gari appears to be consumed more due to its relatively longer shelf-life compared to other food products from cassava as well as its ease of preparation (Omueti et al., 1993; Oyeyinka et al., 2019b).

Gari is a creamy-white, partially gelatinized, roasted free-flowing granular flour made from fermented cassava roots (Sanni et al., 2008). During its production, fermentation plays an important role by hydrolyzing linamarin into hydrocyanic acid at reduced levels that may become harmless after roasting (Irtwange and Achimba, 2009; Laya et al., 2018). Production of gari involves peeling of cassava roots, followed by washing, and grating to produce cassava mash. The mash is bagged using a porous sack and then allowed to ferment for 3-5 days. Thereafter, the fermented mash is placed in an adjustable press machine for 1-3 hours to remove excess starchy water. The mash is then sieved and roasted (garified). As previously noted, the cassava root used in the preparation of gari and other fermented food products have a very short shelf-life of about three days. Hence, efforts have been made to reduce the rate of deterioration of the roots.

Several factors including age, season at which cassava storage roots are harvested, variety, type of storage and duration has been found to influence the physicochemical, functional, and sensory properties of gari (Laya et al., 2018; Oyeyinka et al., 2019b). Laya et al. (2018) reported that gari produced in the dry 
season were better in terms of physicochemical, functional, and sensory properties than that produced in the rainy season. Oyeyinka et al. (2019b) reported that gari may be produced from deep frozen cassava roots without substantial changes in the eating quality, but the functional properties i.e. swelling capacity was reported to reduce significantly. Furthermore, the authors hypothesized that the freezing conditions, which may generate ice-crystals could have resulted in high starch damage leading to greater reduction in granule size. This presumably resulted in the decrease ability of the samples to absorb moisture and swell. Hence refrigeration may be a better alternative to freezing in this regard. Therefore, this study investigated the physicochemical properties of gari prepared from refrigerated cassava roots for a period of three weeks.

\section{MATERIALS AND METHODS \\ Materials}

Fresh mature cassava roots of variety TME 419 were harvested from the University of Ilorin, Agricultural Research Farm. The cassava roots were immediately transferred to the food processing laboratory in the Department of Home Economics and Food Science, University of Ilorin for processing. All other chemicals used were laboratory-grade.

\section{Storage of Cassava Roots}

Cassava roots were washed in distilled water, drained and weighed. The washed samples, $10 \mathrm{~kg}$ each, were packaged in Ziploc bags and kept in a refrigerator operating at a temperature of $4{ }^{\circ} \mathrm{C} \pm 2$. The roots were stored for a period 1,2 and

3 weeks. Cassava roots that were immediately processed after harvest served as the control.

\section{Preparation of Gari}

Gari was prepared from either fresh or stored cassava roots as reported previously (Oyeyinka et al., 2019b). Briefly, cassava roots were peeled, washed and grated using a Lister Diesel (5-1 6HP 650RPM, UK) grating machine. The grated pulp was packed into a jute bag and pressed to remove water. The pulp was fermented for 5 days, sifted to remove coarse fibre and roasted to obtain gari. 


\section{Analyses}

\section{Colour}

The tristimulus $L, a, b$ parameters of the gari samples were determined after standardization with a white tile using a Colorflex-EZ bench top spectrophotometer (A60-1014-593, Hunter Associates, Reston, VA, USA). Digital color photos were taken in duplicate and values read directly from a digital print (Oyeyinka et al., 2019a).

\section{Particle Size Distribution}

The particle size of the gari samples was determined as earlier reported (Oyeyinka et al., 2019b). Briefly, fifty (50) grams of gari was sieved through a set of graded Tyler sieves of aperture sizes 5.00, 4.00, 3.0, 1.80, 1.40 and $1.00 \mathrm{~mm}$ using a Retsch Vibro shaker (Model 65056, W. Germany) set at frequency of 50 $\mathrm{Hz}$ for 10 min. Fractions retained on each sieve were then weighed.

\section{Swelling Capacity}

Swelling capacity was determined by filling gari samples into a $50 \mathrm{~mL}$ glass measuring cylinder. Distilled water was added at room temperature to give a total volume of $50 \mathrm{~mL}$. The top of the cylinder was tightly covered and the contents mixed by inverting the cylinder. After 2 min, the cylinder was inverted again. The cylinder was then left to stand for additional $3 \mathrm{~min}$ and the final volume occupied by the gari was recorded. Swelling capacity was determined by dividing the volume of gari in water by the initial volume of gari (Oyeyinka et al., 2019b).

\section{Bulk Densities}

Loose and packed bulk densities of gari samples were determined as earlier reported (Falade and Oyeyinka, 2015). Sample was filled to $100 \mathrm{~mL}$ mark of a measuring cylinder $(100 \mathrm{~mL})$ and the content weighed. Packed bulk density was also obtained by following the same procedure, but with additional tapping for 50 times prior to weighing. Bulk density was calculated as the ratio of the bulk weight and the volume of the container $(\mathrm{g} / \mathrm{mL})$.

\section{Chemical Composition}

Moisture, crude fat and total ash contents were determined using the standard method of the Association of official Analytical Chemists (2000). Protein content was determined using the Kjeldahl method $(6.25 \times \mathrm{N})$ and total carbohydrate was calculated by difference. Crude fibre were determined by standard laboratory procedure (Olagunju et al., 2018). The $\mathrm{pH}$ of the samples was determined using 
a pH meter (Jenway 3505, Bibby Scientific, London, UK), while cyanide contents were determined by the method of Nkoudou and Essia, (2017).

\section{Pasting Properties}

The pasting properties of the gari were determined using a Rapid Visco-Analyzer (Newport Scientific Australia) as previously reported (Nwancho et al., 2014).

\section{Sensory Properties}

Sensory evaluation of gari was carried out as using a multiple comparison test. Thirty (30) panelists, selected from student of the Department of Home Economics and Food Science, University of Ilorin, Nigeria were used for the evaluation. The selected students were those who consume gari regularly. Prior to the sensory analysis, they were screened with respect to their interest and ability to differentiate food sensory properties. The samples were evaluated for aroma, appearance, sourness, and overall acceptability using a 9-point hedonic scale, where 9 and 1 represent like extremely and dislike extremely, respectively.

\section{Statistical Analysis}

Duplicate samples were prepared and analyses done in triplicate. Data was analysed using one-way analysis of variance (ANOVA) and means were compared using the Fisher Least Significant Difference (LSD) test $(p \leq 0.05)$ using the Statistical Package for the Social Sciences (SPSS) Version 16.0 for Windows (SPSS Inc., Chicago, IL, USA).

\section{RESULTS AND DISCUSSION Colour}

Refrigeration slightly affected the objective colour attributes of the gari samples (Table 1). In general, gari prepared from refrigerated cassava root showed lower lightness $(L)$ values (64.40-70.30) compared with the one prepared from freshly harvested cassava root (70.48). The $L$ value decreased with increasing refrigeration period. Gari prepared from cassava root refrigerated for 1 week had similar $L$ value with the control. Beyond one week of storage, the $L$ value decreased significantly $(P<0.05)$. Oyeyinka et al. $(2019 \mathrm{~b})$, similarly reported decrease in $L$ values for gari prepared from frozen cassava roots. The $a$ and $b$ values of the gari samples did not follow a particular trend. Redness value (positive a) ranged between 2.60 and 3.11, while the yellowness value (positive b) of the sample ranged between 11.28 and 13.07 . 
Table 1. Colour attributes, moisture and carbohydrate contents of gari from refrigerated cassava

\begin{tabular}{|c|c|c|c|c|c|}
\hline $\begin{array}{l}\text { Storage } \\
\text { period } \\
\text { (Weeks) }\end{array}$ & $\mathrm{L}$ & $\mathrm{a}$ & $\mathrm{b}$ & Moisture (\%) & ${ }^{*} \mathrm{CHO}(\%)$ \\
\hline 0 & $70.48^{a} \pm 0.96$ & $2.71^{b} \pm 0.11$ & $12.83^{a} \pm 0.40$ & $7.75^{a} \pm 0.04$ & $87.80^{a} \pm 0.15$ \\
\hline 1 & $70.30^{a} \pm 2.04$ & $3.11^{\mathrm{a}} \pm 0.18$ & $13.07^{a} \pm 0.97$ & $7.37^{a} \pm 1.07$ & $88.25^{a} \pm 1.07$ \\
\hline 2 & $65.64^{b} \pm 0.70$ & $2.81^{b} \pm 0.20$ & $\begin{array}{l}12.30^{\mathrm{ab}} \pm \\
0.51\end{array}$ & $7.68^{a} \pm 0.07$ & $88.13^{a} \pm 0.11$ \\
\hline 3 & $64.40^{b} \pm 4.33$ & $2.60^{b} \pm 0.21$ & $11.28^{b} \pm 1.25$ & $7.35^{a} \pm 0.18$ & $88.08^{a} \pm 0.18$ \\
\hline
\end{tabular}

Values are mean \pm standard deviation. Mean with different superscripts along a column are significantly $(p<0.05)$ different

${ }^{*} \mathrm{CHO}$ : Carbohydrate

\section{Chemical Composition}

The carbohydrate (average of $88 \%$ ) and moisture (average of $7.5 \%$ ) contents of the gari samples were very similar (Table 1), suggesting that the refrigeration condition did not alter the composition of cassava roots from which the gari samples were made. Carbohydrate content of the samples was very high and this could be because the bulk of cassava roots is carbohydrate (Oyeyinka et al., 2019a). The carbohydrate and moisture values in this study are in agreement with earlier studies (Laya et al., 2018; Oyeyinka et al., 2019b) and also within values that are known to be safe for storage between two and seven months (Ukpabi and Ndimele, 1990). Laya et al. (2018) found that the period of harvest of cassava influenced the carbohydrate contents of gari. Gari prepared from cassava harvested in the dry season at 12 months after planting (MAP) reportedly showed higher carbohydrate content (65.98-75.12\%) compared with the one produced from cassava harvested in the raining season (49.58-68.47\%) at 15 months MAP (Laya et al., 2018).

\section{pH and Cyanide Content}

The $\mathrm{pH}$ values of the gari sample decreased significantly $(\mathrm{p}<0.05)$ from 5.40 to 4.30 (Figure 1). Gari is a fermented product with $\mathrm{pH}$ found to vary between 3.42 and 4.88 depending on processing methods (Oyeyinka et al., 2019b; Sanni et al., 2008). Cassava roots has a high $\mathrm{pH}$, which may vary between 6.9 and 7.1 (Oyewole and Afolami, 2001). The reduction in $\mathrm{pH}$ is associated with fermentation 
period due to the production of organic acids. These acids contribute largely to the flavour and consequently the acceptability of gari. Furthermore, high acidity of gari has been associated with better stability of gari and the resulting products such as eba, when compared to other food products such as pounded yam (Ogunsua, 1980).

Cyanide levels $(2.96 \mathrm{mg} / \mathrm{kg})$ in the gari from freshly processed cassava roots were significantly $(p<0.05)$ higher than samples $(1.90-2.38 \mathrm{mg} / \mathrm{kg})$ obtained from refrigerated cassava roots (Figure 1 ). The cyanide contents decreased with increasing refrigeration period from 2.96 to $1.90 \mathrm{mg} / \mathrm{kg}$ and the values are within the value $(10 \mathrm{mg} / \mathrm{kg}$ ) considered safe (Sanni et al., 2008). Oyeyinka et al. (2019b) reported higher cyanide levels $(4.48-6.41 \mathrm{mg} / \mathrm{kg})$ for gari prepared from frozen cassava roots compared to values $(1.90-2.96 \mathrm{mg} / \mathrm{kg})$ reported in this study. Laya et al. (2018) also reported varying cyanide contents $(0.08-0.90 \mathrm{mg} / \mathrm{kg})$ for cassava roots harvested at different periods. The variation in cyanide contents may be attributed to the variety of cassava used as well as the duration of fermentation used in the respective studies. Consumption of high levels of cyanide has been associated with serious health disorders, especially when consumed in quantities exceeding the recommended safe levels (Montagnac et al., 2009).

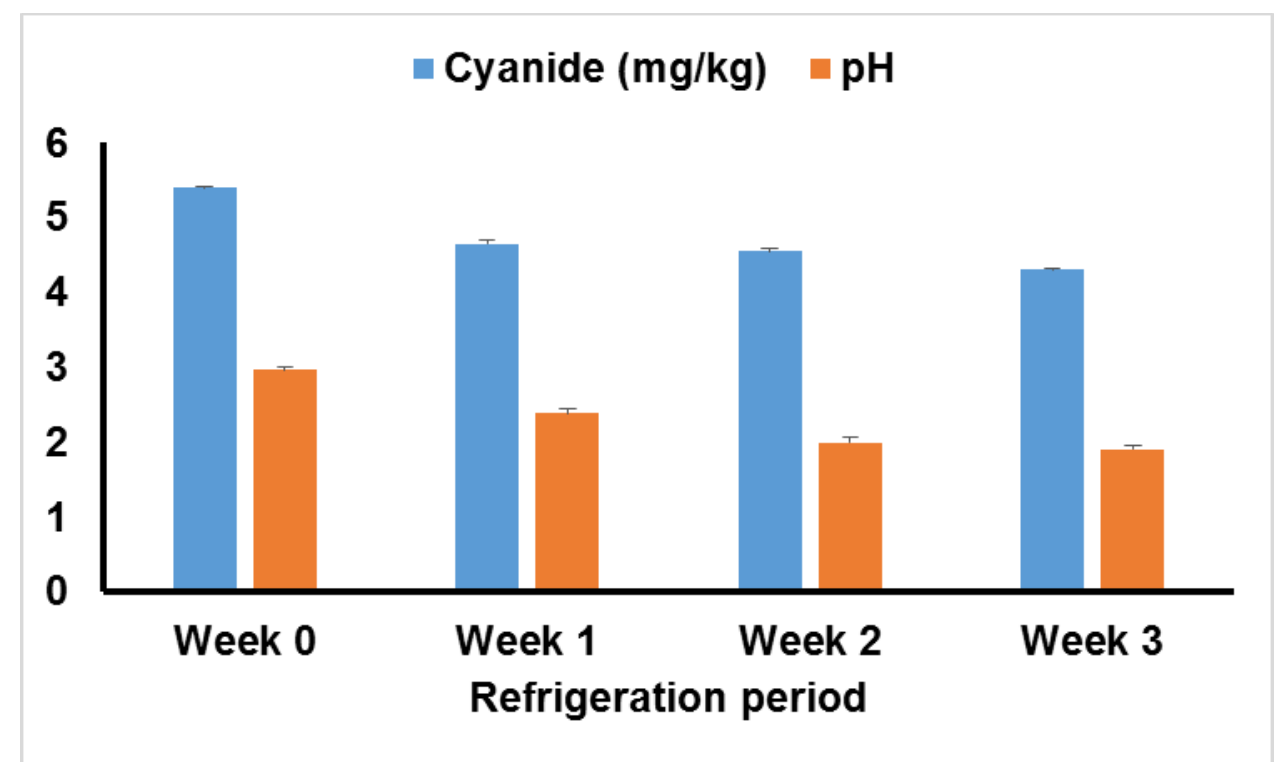

Figure 1: $\mathrm{pH}$ and cyanide contents of gari from refrigerated cassava Error bars indicate standard deviation $(\mathrm{N}=6)$ 


\section{Particle Size Distribution}

The particle size of garivaried significantly $(p<0.05)$ among the samples, but did not follow any particular trend with weeks of refrigeration (Table 2). Oduro et al. (2000) suggested that differences in particle size distribution of gari samples could be as a result of varying grating procedures, roasting processes and the duration of fermentation. However, it is unlikely that any of the above-mentioned factors led to the observed variation in particle size in this study, since the samples were subjected to the same grating procedure, roasting process and period of fermentation. Gari obtained from freshly harvested cassava roots, which served as the control, had a lower amount (3.19) of fine particles compared with the gari (5.21-19.80) from refrigerated cassava roots. Our finding is in agreement with previous reports on gari from frozen cassava roots where gari from freshly harvested roots similarly had finer particles than stored roots (Oyeyinka et al., $2019 b)$. Several factors including the extent of starch damage may influence the particle size of gari samples (Akingbala et al., 2005).

Table 2. Particle size distribution of gari from refrigerated cassava

\begin{tabular}{llllllll}
\hline $\begin{array}{l}\text { Storag } \\
\text { e } \\
\text { period } \\
\text { (Week } \\
\mathrm{s})\end{array}$ & $1 \mathrm{~mm}$ & $1.4 \mathrm{~mm}$ & $1.8 \mathrm{~mm}$ & $3 \mathrm{~mm}$ & $4 \mathrm{~mm}$ & $5 \mathrm{~mm}$ & $\begin{array}{l}\text { Fine } \\
\text { particles }\end{array}$ \\
\hline 0 & $0.28^{\mathrm{b}} \pm 0.0$ & $2.44^{\mathrm{b}} \pm 0.0$ & $24.99^{\mathrm{a}} \pm 0.0$ & $52.99^{\mathrm{a}} \pm 0$. & $10.75^{\mathrm{b}} \pm 0$. & $5.48^{\mathrm{b}} \pm 0.03$ & $3.19^{\mathrm{c}} \pm 0.01$ \\
& 1 & 1 & 1 & 04 & 08 & & \\
1 & $0.10^{\mathrm{b}} \pm 0.0$ & $2.95^{\mathrm{b}} \pm 0.0$ & $16.15^{\mathrm{b}} \pm 0.0$ & $53.29^{\mathrm{a}} \pm 0$. & $15.16^{\mathrm{a}} \pm 0$. & $6.92^{\mathrm{b}} \pm 0.12$ & $6.37^{\mathrm{b}} \pm 0.19$ \\
& 1 & 7 & 8 & 01 & 08 & & \\
2 & $0.85^{\mathrm{b}} \pm 0.0$ & $1.07^{\mathrm{c}} \pm 0.3$ & $14.06^{\mathrm{c}} \pm 0.0$ & $74.78^{\mathrm{a}} \pm 1$. & $10.49^{\mathrm{b}} \pm 3$. & $6.78^{\mathrm{b}} \pm 1.70$ & $5.21^{\mathrm{bc} \pm 1.7}$ \\
& 6 & 7 & 1 & 13 & 08 & & 5 \\
3 & $0.78^{\mathrm{a}} \pm 0.1$ & $3.51^{\mathrm{a}} \pm 0.0$ & $9.34^{\mathrm{d}} \pm 0.02$ & $43.36 \mathrm{a} \pm 0$. & $18.49^{\mathrm{a}} \pm 0$. & $12.24^{\mathrm{a}} \pm 0.0$ & $19.80^{\mathrm{a}} \pm 0.2$ \\
& 4 & 1 & & 01 & 02 & 1 & 8 \\
\hline \multicolumn{7}{c}{ Values are mean \pm standard deviation. Mean with different superscripts along a column are significantly $(\mathrm{p}<0.05)$} \\
\end{tabular}

\section{Functional Properties}

Swelling capacity is the ability of samples to absorb water and swell at room temperature. It is highly important as it measures the extent of gelatinization of the gari sample and a high swelling capacity is very important and desirable for good quality gari. The swelling capacity of gari varied significantly $(p<0.05)$ among the samples and decreased slightly with increasing refrigeration period 
(Figure 2). The swelling capacity recorded in this study is within the range (1.64.63) reported in the literature (Akingbala et al., 2005; Nwancho et al., 2014). Differences in the swelling capacity of gari has been associated with variation in particle size, which largely depends on the associative forces between the particles (Sanni et al., 2008). Particles with low associative force between them will exhibit high swelling capacity. The swelling capacity of gari was found to decrease with reduction in the particle size (Nwancho et al., 2014).

The packed bulk densities (PBD) of the gari samples were higher than the loosed bulk density $(\mathrm{LBD})$. The PBD and LBD significantly $(p<0.05)$ decreased with increasing refrigeration period which agrees with previous research (Oyeyinka et al., 2019b). Food samples with low bulk densities are advantageous as more economical packaging materials can be used for their distribution (Falade and Oyeyinka, 2015). The PBD and LBD values are in agreement with the literature (Nwancho et al., 2014; Oyeyinka et al., 2019b).

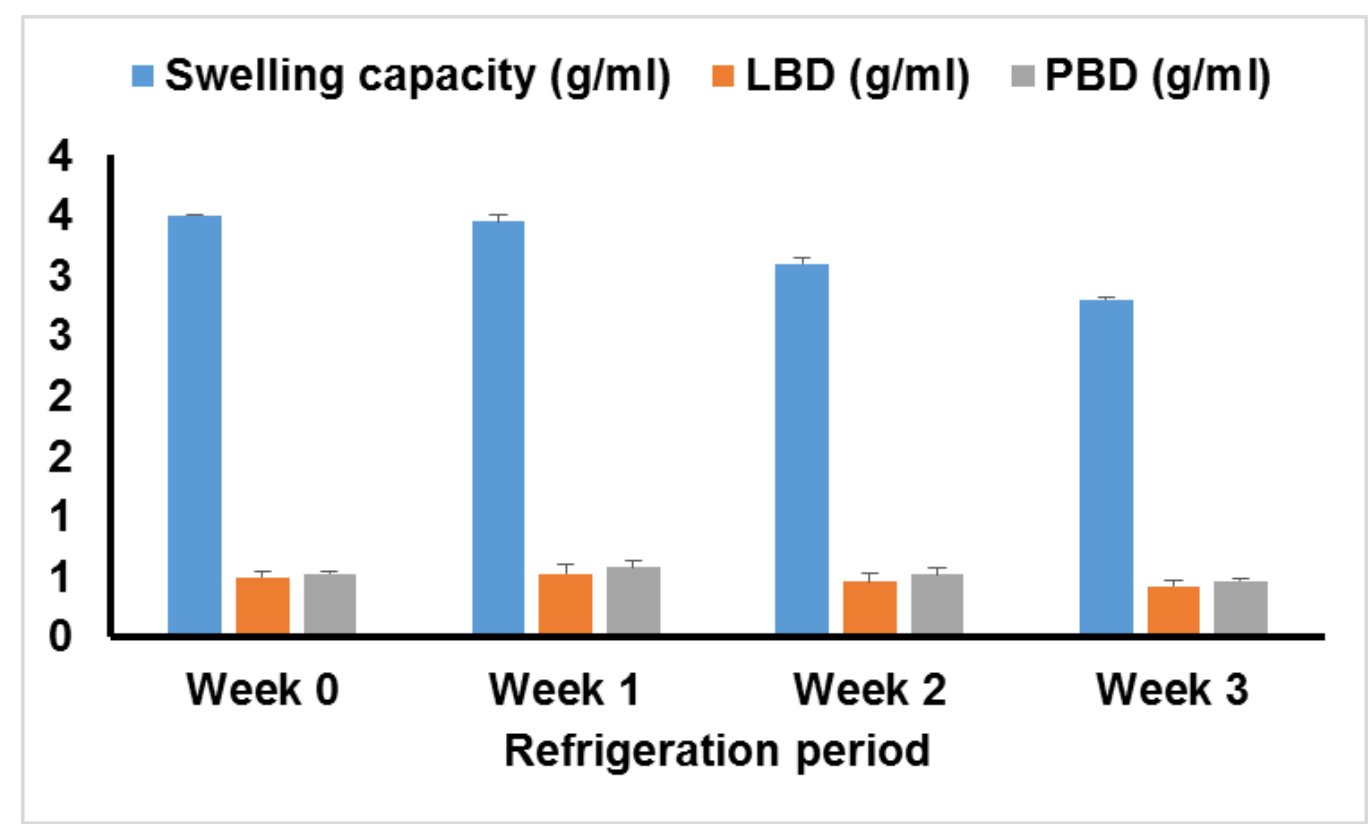

Figure 2. Selected functional properties of gari from refrigerated cassava Error bars indicate standard deviation $(\mathrm{N}=6)$

\section{Pasting Properties}

Refrigeration of cassava roots significantly $(p<0.05)$ affected the pasting properties of the gari produced from the roots. The pasting curves of the samples are presented in Figure 3. Gari from freshly harvested roots displayed a lower peak viscosity (2562 cP) compared to samples from refrigerated cassava roots 
(2897-6071 cP). High peak viscosity is an indication of high starch content and also relates to water binding capacity of starch (Oyeyinka et al., 2019b). The variation in the peak viscosity of the gari samples may be linked with the differences in particle size (Table 2). Gari samples with greater proportion of small particles displayed higher peak viscosity. A previous study similarly found that the peak viscosity of gari samples was significantly affected by their particle size (Nwancho et al., 2014).

There was no significant difference $(p>0.05)$ in the trough viscosity of the gari samples except for gari from roots refrigerated for 3 weeks. The values ranged from $2430.50 \mathrm{cP}$ for gari from freshly harvested roots to $4640.50 \mathrm{cP}$ for gari from roots refrigerated for 3 weeks. Breakdown viscosity, which measures the susceptibility of starch granules to disintegrate during heating (Oyeyinka et al., 2019b) varied between 132 - $635.50 \mathrm{cP}$. Gari from refrigerated cassava roots generally showed higher breakdown viscosity compared to gari from freshly harvested cassava roots, suggesting that gari from freshly harvested roots is more stable to heat and mechanical shear than gari from refrigerated cassava roots. The impact of refrigeration on breakdown viscosity was only significant after the second week of storage. Final viscosity is commonly used to define the quality of a particular starch-based sample, as it indicates the ability of the material to form a viscous paste or gel after cooking and cooling as well as the resistance of the paste to shear force during stirring (Sanni et al., 2008). Final viscosity values for the gari from refrigerated cassava were generally higher than the control, indicating that gari from refrigerated cassava roots will form a more viscous and stable paste after cooking and cooling. Setback viscosity values followed the same trend as observed for final viscosity. Gari from freshly harvested cassava roots had the lowest setback viscosity $(1241 \mathrm{cP})$ compared to gari from refrigerated cassava roots which ranged from $(1318-1924 \mathrm{cP})$. Gari samples showed significant $(p<0.05)$ variations in their peak time $(5.87-7.00$ mins). This implies that refrigeration affected the cooking time of the garisamples by reducing it significantly $(p<0.05)$. The pasting temperatures (average of $86^{\circ} \mathrm{C}$ ) of gari from refrigerated cassava were generally lower than that of the control sample $\left(91.23^{\circ} \mathrm{C}\right)$ and is in agreement with the literature (Nwancho et al., 2014; Olanrewaju and Idowu, 2017; Awoyale et al., 2020). Pasting temperature measures the first detectable viscosity and as well depicts the maximum temperature taken to cook a given sample. Refrigeration reduced the pasting temperatures of the gari samples, suggesting that gari from refrigerated roots will cook at a lower temperature than the control. 

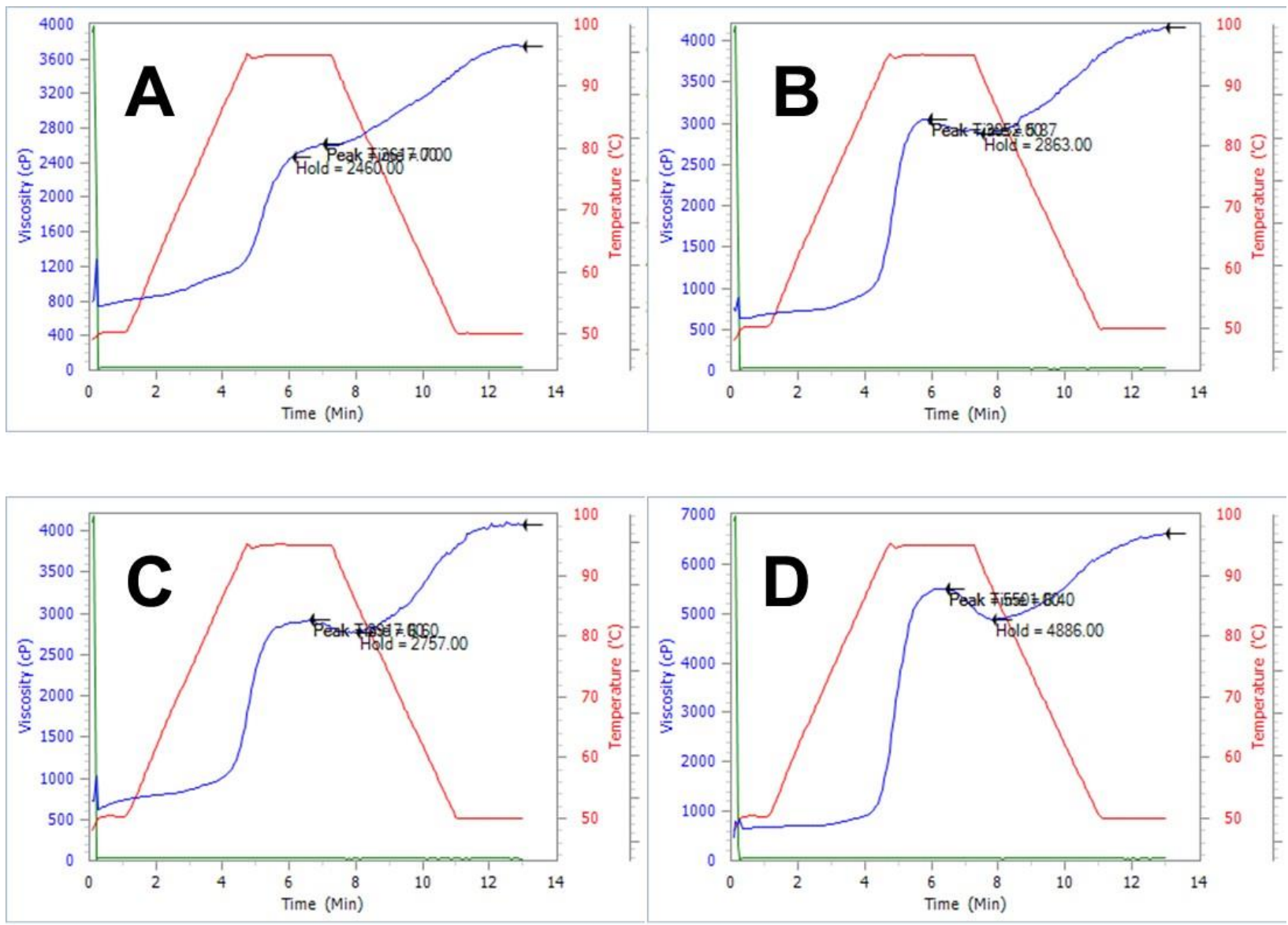

Figure 3. Pasting curve of gari from refrigerated cassava

A: Gari from cassava refrigerated for 0 week

B: Gari from cassava refrigerated for 1 week

C: Gari from cassava refrigerated for 2 weeks

D: Gari from cassava refrigerated for 3 weeks

\section{Sensory Properties}

Refrigeration significantly $(p<0.05)$ affected the sensory properties of the gari samples (Table 3). Gari prepared from cassava roots refrigerated for 3 weeks had substantially lower ratings in appearance, aroma, colour, sourness, texture and overall acceptability compared to other samples. The lower ratings recorded for sample prepared at the third week of refrigeration suggest that cassava roots should not be stored beyond 2 weeks to have acceptable sensory properties. 
Other samples had similar ratings for all the measured sensory properties. Major parameters such as the appearance and sourness are important factors to be considered when determining the quality of gari. Although the preference for sourness of gari may vary depending on processing method used and individual perception, consumers most times determine their choice of gari from its appearance and sour taste. In this study, the control gari sample had slightly lower appearance ratings than gari from cassava roots refrigerated for 1 and 2 weeks.

Table 3. Mean sensory scores of gari from refrigerated cassava

\begin{tabular}{ccccccc}
\hline $\begin{array}{l}\text { Storage } \\
\text { period } \\
\text { (Weeks) }\end{array}$ & Appearance & Aroma & Colour & Sourness & Texture & $\begin{array}{l}\text { Overall } \\
\text { acceptability }\end{array}$ \\
\hline 0 & $7.14^{\mathrm{b}} \pm 0.97$ & $6.60^{\mathrm{b}} \pm 0.86$ & $6.58^{\mathrm{c}} \pm 0.70$ & $7.06^{\mathrm{a}}$ & $6.76^{\mathrm{b}}$ & $6.80^{\mathrm{c}} \pm 0.93$ \\
& & & & \pm 0.87 & \pm 0.82 & \\
1 & $7.82^{\mathrm{a}} \pm 0.69$ & $7.34^{\mathrm{a}} \pm 0.82$ & $7.58^{\mathrm{a}}$ & $7.52^{\mathrm{a}}$ & $7.36^{\mathrm{a}}$ & $8.30^{\mathrm{a}} \pm 0.61$ \\
& & & \pm 0.86 & \pm 0.79 & \pm 0.89 & \\
2 & $7.44^{\mathrm{ab}} \pm 0.86$ & $7.06^{\mathrm{a}} \pm 0.77$ & $7.16^{\mathrm{b}}$ & $7.26^{\mathrm{a}}$ & $7.22^{\mathrm{a}}$ & $7.28^{\mathrm{b}} \pm 0.81$ \\
& & & \pm 0.77 & \pm 0.72 & \pm 0.86 & \\
3 & $3.02^{\mathrm{c}} \pm 1.35$ & \multirow{3}{*}{$3.04^{\mathrm{c}} \pm 1.56$} & $2.40^{\mathrm{d}}$ & $4.80^{\mathrm{b}}$ & $5.18^{\mathrm{c}}$ & $3.00^{\mathrm{d}} \pm 1.07$ \\
& & \pm 1.11 & \pm 2.13 & \pm 1.69 & \\
\hline
\end{tabular}

\section{CONCLUSION}

Refrigeration of cassava roots did not have any influence on the proximate composition of gari obtained from refrigerated cassava roots. However, colour, sensory, pasting properties, loosed and packed bulk density as well as the swelling capacity of gari samples obtained from refrigerated cassava roots were substantially affected by refrigeration. Cassava roots can be refrigerated for a period of 2 weeks without substantial changes in the eating quality of the resulting gari. Future studies are required to investigate the physicochemical properties of starch from refrigerated cassava roots to determine their potentials in food and non-food applications. 


\section{REFERENCES}

Adisa, R. S., Adefalu, L. L., Olatinwo, L. K., Balogun, K. S., and Ogunmadeko, O. O. (2015). Determinants of post-harvest losses of yam among yam farmers in Ekiti State, Nigeria. Bulletin of the Institute of Tropical Agriculture, Kyushu University, 38, 73-78.

Akingbala, J. O., Oyewole, O. B., Uzo-Peters, P. I., Karim, R. O., and BaccusTaylor, G. S. (2005). Evaluating stored cassava quality in gari production. Journal of Food, Agriculture \& Environment, 3, 75-80.

Association of Official Analytical Chemists (AOAC) (2000). Offcial methods of analysis. 17th edition. In: Association of official Analytical Chemists, Rockville.

Awoyale, W., Asiedu, R., Kawalawu, W. K., Abass, A., Maziya-Dixon, B., Kromah, A., Edet, M., and Mulbah, S. (2020). Assessment of the Suitability of Different Cassava Varieties for Gari and Fufu Flour Production in Liberia. Asian Food Science Journal, 14(2), 36-52.

Balogun, M., Karim, O., Kolawole, F., and Solarin, A. (2012). Quality attributes of tapioca meal fortified with defatted soy flour. Agrosearch, 12(1), 61-68.

Falade, K. O., and Oyeyinka, S. A. (2015). Color, Chemical and Functional Properties of Plantain Cultivars and Cooking Banana Flour as Affected by Drying Method and Maturity. Journal of Food Processing and Preservation, 39(6), 816-828.

Falola, A., Salami, M., Bello, A., and Olaoye, T. (2017). Effect of yam storage techniques usage on farm income in Kwara State, Nigeria. Agrosearch, 17(1), 54-65.

FAO/WHO. (1991). Joint FAO/WHO food standards programme. In: FAO Rome, IT.

Ibegbulem, C. O., and Chikezie, P. C. (2018). Comparative proximate composition and cyanide content of peeled and unpeeled cassava roots processed into garri by traditional methods. Research Journal of Food and Nutrition, 2(2), 1-13.

Idowu, M., and Akindele, S. (1994). Effect of storage of cassava roots on the chemical composition and sensory qualities of gari and fufu. Food Chemistry, 51, 421-424.

Irtwange, S., and Achimba, O. (2009). Effect of the duration of fermentation on the quality of gari. Current Research Journal of Biological Sciences, 1(3), 150-154. 
Kajuna, S., Silayo, V., Mkenda, A., and Makungu, P. (2001). Thin-layer drying of diced cassava roots. African Journal of Science and Technology, 2(2), 94-100.

Karim, O., Fasasi, O., and Oyeyinka, S. (2009). Gari yield and chemical composition of cassava roots stored using traditional methods. Pakistan Journal of Nutrition, 8(12), 1830-1833.

Laya, A., Koubala, B. B., Kouninki, H., and Nchiwan Nukenine, E. (2018). Effect of harvest period on the proximate composition and functional and sensory properties of gari produced from local and improved Cassava (Manihot esculenta) varieties. International Journal of Food Science, 6241035, $1-15$.

Montagnac, J. A., Davis, C. R., and Tanumihardjo, S. A. (2009). Processing techniques to reduce toxicity and antinutrients of cassava for use as a staple food. Comprehensive Reviews in Food Science and Food Safety, 8(1), 17-27.

Nkoudou, N. Z., and Essia, J. J. N. (2017). Cyanides reduction and pasting properties of cassava (Manihot Esculenta Crantz) flour as affected by fermentation process. Food and Nurtrition Sciences, 8(3), 326-333.

Nwancho, S., Ekwu, F., Mgbebu, P., Njoku, C., \& Okoro, C. (2014). Effect of particle size on the functional, pasting and textural properties of gari produced from fresh cassava roots and dry chips. International Journal of Engineering and Science, 3(3), 50-55.

Oduro, I., Ellis, W., Dziedzoave, N., and Nimako-Yeboah, K. (2000). Quality of gari from selected processing zones in Ghana. Food control, 11(4), 297303.

Ogunsua, A. O. (1980). Changes in some chemical constituents during the fermentation of cassava tubers (Manihot esculenta, Crantz). Food Chemistry, 5(3), 249-255.

Olagunju, O. F., Ezekiel, O. O., Ogunshe, A. O., Oyeyinka, S. A., and ljabadeniyi, O. A. (2018). Effects of fermentation on proximate composition, mineral profile and antinutrients of tamarind (Tamarindus indica L.) seed in the production of daddawa-type condiment. LWT-Food Science and Technology, 90, 455-459.

Olanrewaju, A. S., and Idowu, O. E. (2017). Quality assessment of Cassava Gari produced in some selected local governments of Ekiti state, Nigeria. American Journal of Food Science and Nutrition, 4(4), 36-41. 
Omueti, O., Amusan, J., Fayemi, T., and Asiiye, K. (1993). Evaluation of "gari" from markets and processing centres for cyanide and moisture contents in some states in Nigeria. Nigerian Food Journal, 11, 135-144.

Oyewole, O., and Afolami, O. (2001). Quality and preference of different cassava varieties for'lafun'production. Journal of Food Technology in Africa, 6(1), 27-29.

Oyeyinka, S., Adeloye, A., Smith, S., Adesina, B., and Akinwande, F. (2019a). Physicochemical properties of flour and starch from two cassava varieties. Agrosearch, 19(1), 28-45.

Oyeyinka, S. A., Ajayi, O. I., Gbadebo, C. T., Kayode, R. M., Karim, O. R., and Adeloye, A. A. (2019b). Physicochemical properties of gari prepared from frozen cassava roots. LWT-Food Science and Technology, 99, 594-599.

Oyeyinka, S. A., Adeloye, A. A., Olaomo, O. O., and Kayitesi, E. (2020). Effect of fermentation time on physicochemical properties of starch extracted from cassava root. Food Bioscience, 33, 100485.

Sanni, L., Adebowale, A., Awoyale, W., and Fetuga, G. (2008). Quality of gari (roasted cassava mash) in Lagos State, Nigeria. Nigerian Food Journal, 26, 125-134.

Uchechukwu-Agua, A. D., Caleb, O. J., and Opara, U. L. (2015). Postharvest handling and storage of fresh cassava root and products: a review. Food and Bioprocess Technology, 8, 729-748.

Ukpabi, U., and Ndimele, C. (1990). Evaluation of the quality of gari produced in Imo State, Nigeria. Nigerian Food Journal, 8, 105-109. 